\title{
Mouse retrovirus mediates porcine endogenous retrovirus transmission into human cells in long-term human-porcine chimeric mice
}

\author{
Yong-Guang Yang, ${ }^{1}$ James C. Wood, ${ }^{2}$ Ping Lan, ${ }^{1}$ Robert A. Wilkinson, ${ }^{3}$ Megan Sykes, ${ }^{1}$ \\ Jay A. Fishman, ${ }^{3}$ and Clive Patience ${ }^{2}$ \\ ${ }^{1}$ Transplantation Biology Research Center, Massachusetts General Hospital, Harvard Medical School, Boston, Massachusetts, USA. \\ 2Immerge BioTherapeutics Inc., Cambridge, Massachusetts, USA. ${ }^{3}$ Infectious Disease Division, Massachusetts General Hospital, \\ Harvard Medical School, Boston, Massachusetts, USA.
}

\begin{abstract}
Porcine endogenous retrovirus (PERV) is a potential pathogen in clinical xenotransplantation; transmission of PERV in vivo has been suggested in murine xenotransplantation models. We analyzed the transmission of PERV to human cells in vivo using a model in which immunodeficient NOD/SCID transgenic mice were transplanted with porcine and human lymphohematopoietic tissues. Our results demonstrate, we believe for the first time, that human and pig cells can coexist long-term (up to 25 weeks) without direct PERV infection of human cells. Despite the transplantation of porcine cells that did not produce human-tropic PERV, human cells from the chimeric mice were frequently found to contain PERV sequences. However, this transmission was due to the pseudotyping of PERV-C (a virus without human tropism) by xenotropic murine leukemia virus, rather than to de novo generation of human-tropic PERV. Thus, pseudotyping might account for the PERV transmission previously observed in mice. The absence of direct human cell infection following long-term in vivo coexistence with large numbers of porcine cells provides encouragement regarding the potential safety of using pigs that do not produce human-tropic PERV as source animals for transplantation to humans.
\end{abstract}

\section{Introduction}

Xenotransplantation of swine tissues has been proposed as a means to alleviate the shortage of organs and tissues needed for the treatment of human organ failure and cellular diseases such as diabetes mellitus (1). However, concerns have been raised about possible transmission of pig-derived pathogens to xenograft recipients $(2,3)$. Particular attention has focused on the porcine endogenous retroviruses (PERVs) that are present in pig genomes and that possess limited replication competence for certain human cell lines in vitro (4-7). Recently, exogenous forms of recombinant human-tropic PERV that grow to high titers in vitro have been identified in healthy swine. This indicates that the potential risk for human infection by PERV may be influenced more by the presence of exogenous PERV than by replication-competent germ-line PERV loci (8).

The possibility of interspecies infection by PERV in vivo has been suggested by studies of immunodeficient mice that demonstrate low-level PERV infection following the transplantation of porcine islets (9-11). These studies stand in contrast to the lack of infection detected in nonhuman primates (12-15) and several small laboratory animal species $(12,16)$. Similarly, it has not been possible to demonstrate PERV infection in patients exposed to living porcine tissues (17-23).

Nonstandard abbreviations used: BM, bone marrow; CCR5, CC chemokine receptor 5; MLV, murine leukemia virus; MLV-X, xenotropic MLV; MS, miniature swine; NOD/SCID-Tg, NOD/SCID transgenic; PAEC, primary aortic endothelial cell; PERV, porcine endogenous retrovirus; RT, reverse transcriptase; SLA, swine leukocyte antigen.

Conflict of interest: The authors have declared that no conflict of interest exists.

Citation for this article: J. Clin. Invest. 114:695-700 (2004)

doi:10.1172/JCI200421946
To date, PERV transmission to human cells in vivo has not been assessed in patients or animal models that involve long-term exposure of human cells to comparable amounts of porcine tissues. To analyze the transmission of PERV to human cells in vivo, we developed a new xenotransplantation model in which human cells coexist with large numbers of porcine cells. NOD/SCID transgenic (NOD/SCID-Tg) mice that produce porcine cytokines were transplanted with porcine bone marrow (BM) cells and human lymphohematopoietic tissues. The human cells from chimeric mice were frequently found to contain PERV sequences. However, this infection resulted from the pseudotyping of PERV by an endogenous retrovirus of mice, murine leukemia virus (MLV).

\section{Results}

PERV transmission profile of donor pig cells. We determined the PERV transmission characteristics of PBMCs, primary aortic endothelial cells (PAECs), and BM cells from miniature swine (MS) using in vitro coculture with human 293 cells. The PBMCs, PAECs, and BM cells of MS nos. 15101 and 14813 did not transmit PERV to human cells in vitro but productively infected porcine cells with PERV-C (data not shown). In contrast, the PBMCs, PAECs, and thymic stroma cells of MS 13605 each produced PERV that infected porcine and human cells. We used only cells from MS 15101 and 14813, which did not transmit PERV to human cells in vitro, for all in vivo transplantation and subsequent in vitro coculture studies.

Induction of mixed hematopoietic chimerism in vivo. We produced $\mathrm{pig} /$ human/mouse triple-chimeric mice by transplantation of porcine BM cells and human fetal thymus and liver tissues into NOD/SCID-Tg mice (24). Similarly, we produced double-chimeric mice possessing both mouse and human, or mouse and pig, 
Table 1

Purified human cells from triple-chimeric mice show evidence of PERV infection

\begin{tabular}{|c|c|c|c|c|}
\hline $\begin{array}{l}\text { Group and } \\
\text { mouse no. }\end{array}$ & $\begin{array}{l}\text { Sorted } \\
\text { cells }\end{array}$ & $\begin{array}{c}\text { PERV-pol copies } \\
\pm \text { SD }\end{array}$ & $\begin{array}{c}\text { Pig-MHC copies } \\
\pm \text { SD }\end{array}$ & $\begin{array}{l}\text { Pol:MHC } \\
\text { ratio }\end{array}$ \\
\hline \multicolumn{5}{|c|}{ Porcine BM cells } \\
\hline 4790 & Pig (control) & $195,096 \pm 36,800$ & $5,941 \pm 279$ & 33 \\
\hline \multicolumn{5}{|c|}{ Porcine BM + human fetal thymus/liver } \\
\hline 4676 & Human & $3,141 \pm 630$ & $26 \pm 3$ & $135^{\mathrm{A}}$ \\
\hline 4688 & Human & $849 \pm 136$ & $12 \pm 3$ & $71^{A}$ \\
\hline 507 & Human & $13,249 \pm 725$ & $178 \pm 20$ & $74 \mathrm{~A}$ \\
\hline 518 & Human & $652 \pm 61$ & $5 \pm 1$ & $130^{A}$ \\
\hline 4788 & Human & $1,403 \pm 164$ & $14 \pm 2.2$ & $94^{\mathrm{A}}$ \\
\hline \multicolumn{5}{|c|}{ Human fetal thymus/liver } \\
\hline 4794 & Human & $8 \pm 7$ & $<3$ & ND \\
\hline 503 & Human & $49 \pm 37$ & $<3$ & ND \\
\hline 510 & Human & $<7$ & $<3$ & ND \\
\hline
\end{tabular}

Mice were transplanted with porcine BM cells, porcine BM plus human fetal thymus/liver tissues, or human fetal thymus/liver tissues. We prepared DNA from either human cells (700-14,000 depending on cell yield from the sorted chimeric tissues) or pig cells purified from the BM cells of the mice 25 weeks after transplantation, and analyzed DNA samples by PCR. The quantitative detection limit of the MHC PCR is 3 copies per reaction. Results reflect the mean \pm SD of 3 assays. ${ }^{A} P<0.05$ according to confidence intervals. ND, not detected.

in the infected human cells was unexpected, as this PERV subgroup has no tropism for human cells. Therefore, to determine whether the PERV-C and/or MLV were responsible for the infection of the primary 293 cell cultures, we exposed secondary 293 cell cultures to the supernatants of the primary infected cultures. The secondary cultures became productively infected (RT-positive) (Table 3 and Figure 2). By PCR analysis, we found that whereas MLV sequences were still present, $\mathrm{PERV}$-C sequences had become undetectable, indicating that replication-competent MLV was responsible for the productive infection of the 293 cultures. We sequenced the MLV env PCR amplicon and found that it showed high sequence similarity to xenotropic MLV (MLV-X) (Table 4). Taken together, these results indicate that MLV-X can be recovered from the cells of NOD/SCID mice and can transiently expand the tropism of PERV in human cells by pseudotyping.

PERV transmission by hematopoietic cells in vitro. To confirm whether MLV-X is responsible for PERV transmission in the chimeric mice, we

cells by transplantation of human fetal thymus/liver or porcine $\mathrm{BM}$ cells, respectively. Flow cytometric analysis indicated that high levels of human and pig cell chimerism persisted in NOD/SCID$\mathrm{Tg}$ mouse recipients throughout the experimental period (25-26 weeks) (Figure 1) (24).

PERV infection of human cells in vivo. We sorted human cells from 20 triple-chimeric mice 25 weeks after transplantation. Despite stringent sorting conditions, many samples showed evidence of persistent low levels of residual pig cells, according to quantitative PCR analysis (Table 1 and data not shown). In samples from 5 of the 20 mice, we found that the ratio between the copy number of PERV and that of an internal control pig-genome sequence (MHC) was significantly higher than that which could be attributed to contamination by small numbers of residual pig cells (Table 1; $P<0.05)$. These results are consistent with, but do not prove, infection by PERV of human cells. To further characterize the PERV that appeared to have infected the human cells, we performed additional in vitro BM coculture studies.

Retrovirus transmission from bone marrow following mixed hematopoietic chimerism in vivo. We isolated BM cells from chimeric mice in two independent experiments and cocultured them with human 293 cells. The 293 cells became productively infected - that is, they showed reverse transcriptase (RT) activity - following coculture with BM cells from mice transplanted with either pig cells alone or both pig and human cells (Table 2). In contrast, $\mathrm{BM}$ cells from mice that had received only human cells did not infect 293 cells (Table 2).

To identify the retrovirus present in these cocultures, we analyzed the infected 293 cells and chimeric BM samples for the presence of PERV and for MLV sequences, using PCR and sequencing. We found that all of the infected 293 cells had acquired both PERV-C and MLV (env) sequences, but no PERV-A, PERV-B, or recombinant human-tropic PERV-A/C sequences (Table 3 ). In addition, we did not detect recombinant human-tropic PERV-A/C sequences in the porcine donor BM at the time of implantation or at explantation (Table 3 and Figure 2). Our identification of PERV-C performed in vitro cocultures of murine BM cells, human fetal liver cells, and porcine BM cells. Once again, we used the nontransmitting MS 15101 that did not infect 293 cells as the source of porcine cells. We maintained cultures in vitro for 8 days using supportive cytokines, after which we added human 293 cells and monitored virus infection by RT production and PCR. We detected infection of the 293 cells in the cocultures containing either pig and mouse cells or pig, mouse, and human cells (Table 5). No infection of 293 cells was observed following coculture with cell populations that did not contain both porcine and murine cells; that is, cocultures containing human and mouse cells, human and pig cells, or individual pig, mouse, or human cells alone did not infect the 293 cells (Table 5). PCR analysis of the infected 293 cells indicated that they had become infected with MLV, but not PERV. These results further support that MLV-X were responsible for the PERV transmission into human cells detected in the chimeric mice (Table 3). Notably, unlike BM cells from the chimeric mice, in vitro coculture of porcine and mouse cells for 8 days failed to

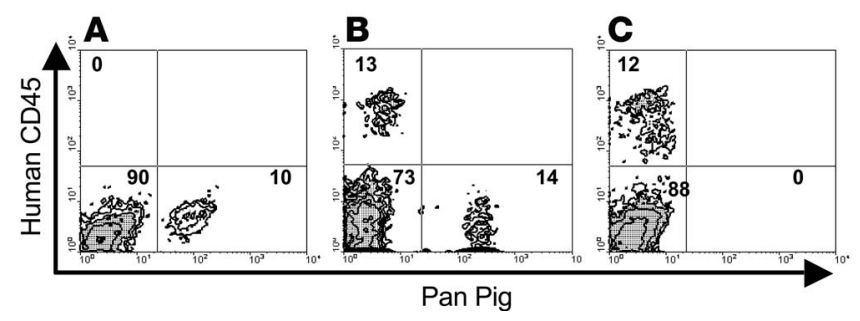

\section{Figure 1}

BM chimerism in NOD/SCID-Tg mice. NOD/SCID-Tg mice demonstrate porcine, human and murine cell chimerism in the BM cells following the transplantation of $(\mathbf{A})$ porcine BM cells alone, $(\mathbf{B})$ porcine BM cells plus human thymus/liver, or (C) human thymus/liver alone. Shown are representative staining profiles of the recipient BM cells at week 25 after transplantation. Murine, human, and pig cells are located in the lower left, upper left, and lower right quadrants, respectively. The percentage of cells in each quadrant is shown. 
Table 2

PERV transmission characteristics of bone marrow cells recovered from chimeric NOD/SCID-Tg mice

$\begin{array}{ccc} & \text { BM source } & \text { RT activity }(\mu \mathrm{U} / \mathrm{ml}) \\ \text { Experiment I } & \text { Mouse + pig } & 7,900 \\ & \text { Mouse + pig + human } & 14,500 \\ & \text { Mouse + human } & <60 \\ \text { Experiment II } & \text { None } & <60 \\ & \text { Mouse + pig } & 54,000 \\ & \text { Mouse + pig + human } & 32,200 \\ & \text { Mouse + human } & <60 \\ \end{array}$

Groups of mice were transplanted with porcine BM cells alone (mouse + pig), human fetal thymus/liver fragments alone (mouse + human), or both (mouse + pig + human). After 25 weeks, we isolated the BM cells from the mice, pooled the BM cells within groups, and analyzed them using 293 cell in vitro transmission assays. $n=3$ mice per group for both experiments.

produce a sufficient amount of replication-competent MLV-Xpseudotyped PERV-C. This suggests that PERV pseudotyping may occur at a relatively low efficiency and that longer observation is required for its detection.

\section{Discussion}

The study of PERV transmission to human cells in vivo has important implications for the ongoing debate regarding the safety of xenotransplantation. In this study, we addressed PERV transmission in a mixed chimerism model using immunodeficient mice in which porcine and human cells coexisted markedly longer than the durations reported previously (9-11). Previously, McIntyre et al. demonstrated the production of replication-competent pig-tropic, but not human-tropic, PERV from porcine BM cells (25). In this study, we extend those findings and show that BM cells are capable of producing replication-competent PERV that can infect human cells. The absence of human-tropic PERV in the McIntyre study was most likely due to the use of cells from nontransmitting pigs, such as those used for this study (MS 15101 and 14813). The ability of BM to produce replication-competent PERV indicates that this tissue is suitable for PERV transmission studies in vivo.

According to a recent report (8), the ability of primary porcine cells to transmit PERV to human cells in vitro has been correlated with the presence of PERV-A/C recombinants. These viruses exist in pigs in vivo but are not derived from the germ-line DNA of the animals (8). Although the mechanism of formation of these viruses is unclear, they presumably arise from the recombination of PERV-A and PERV-C genomes. We did not detect PERV-A/C recombinants in the nontransmitting porcine $\mathrm{BM}$ at the time of implant, consistent with the absence of transmission of PERV to human cells in vitro. Significantly, we did not detect PERV$\mathrm{A} / \mathrm{C}$ recombinants in the porcine or human cells at explantation, even with significant periods of growth together in a xenogeneic environment and with the ongoing production of replication-com- petent PERV-C by the BM cells. Despite the use of nontransmitting porcine cells and the absence of PERV-A/C recombinants, we were still able to detect transmission of PERV to human cells in chimeric mice. This observation raises the concern that grafts might develop the capacity to produce human-tropic PERV in a xenogeneic environment in vivo; this would pose a significant risk for clinical xenotransplantation. However, we have demonstrated that this infection of human cells can be due to pseudotyping of PERV genomes by MLV-X and may be an artifact of the murine model. Equally, the role of pseudotyping in PERV infectivity studies using other model species also warrants consideration.

We conclude that pseudotyping was the sole mechanism by which human cells were infected by PERV because (a) humantropic PERV sequences were not detected in the human cell cocultures; (b) the infected human cells contained PERV-C sequences, and this PERV subgroup is not infectious for human cells $(6,26,27)$; (c) replication-competent MLV-X was identified in the infected human cells; and (d) the tropism of MLV-X includes porcine and human cells. Our identification of MLV-X transmission from murine to human cells is consistent with previous studies demonstrating MLV infection of human cells ex vivo (28, 29). Indeed, isolation of the prototypic MLV-X was first achieved using human xenografts in mice (29). Retroviral pseudotyping is a well-established phenomenon that commonly occurs between retroviruses of the same, and on occasion disparate, phylogenetic families (30), and it has been observed previously between PERV and MLV. For example, MLV core proteins can incorporate PERV envelope (Env) proteins, producing functional pseudotype particles (26), and replication-competent PERV can pseudotype MLV vector transcripts $(31,32)$. In addition, transient pseudotyping of PERV-C genomes into human cell lines by human-tropic PERV has been described (7). Taken together, the above evidence indicates that the most likely route of PERV transmission to human cells in murine models is via the productive infection of pig cells by MLV-X and then subsequent pseudotyping of PERV genome
Table 3

Transmission of PERV-C and MLV sequences to human and porcine cells following in vivo chimerism

\begin{tabular}{|c|c|c|c|c|c|c|c|c|c|}
\hline \multirow[b]{3}{*}{ Sample } & \multirow{3}{*}{$\begin{array}{c}\text { Bone } \\
\text { marrow }\end{array}$} & \multirow{3}{*}{$\begin{array}{c}\mathbf{R T} \\
(\mu \mathrm{U} / \mathrm{ml})\end{array}$} & \multicolumn{7}{|c|}{ PCR result } \\
\hline & & & \multicolumn{4}{|c|}{ PERV subgroup } & \multirow[b]{2}{*}{ MLV } & \multirow[b]{2}{*}{ SLA } & \multirow[b]{2}{*}{ CCR5 } \\
\hline & & & A & B & C & $A / C$ & & & \\
\hline \multirow[t]{3}{*}{ BM } & $\mathrm{M} / \mathrm{P}$ & NT & + & + & + & - & + & + & - \\
\hline & $\mathrm{M} / \mathrm{P} / \mathrm{H}$ & NT & + & + & + & - & + & + & + \\
\hline & $\mathrm{M} / \mathrm{H}$ & NT & - & - & - & - & + & - & + \\
\hline \multirow[t]{4}{*}{ Primary 293} & None & $<60$ & - & - & - & - & - & - & + \\
\hline & $\mathrm{M} / \mathrm{P}$ & 55,000 & - & - & + & - & + & - & + \\
\hline & $\mathrm{M} / \mathrm{P} / \mathrm{H}$ & 32,000 & - & - & + & - & + & - & + \\
\hline & $\mathrm{M} / \mathrm{H}$ & $<60$ & - & - & - & - & - & - & + \\
\hline \multirow[t]{2}{*}{ Secondary 293} & $\mathrm{M} / \mathrm{P}$ & 75,000 & - & - & - & - & + & NT & NT \\
\hline & $\mathrm{M} / \mathrm{P} / \mathrm{H}$ & 27,000 & - & - & - & - & + & NT & NT \\
\hline
\end{tabular}

PCR and RT analysis of chimeric mouse BM cells, and the associated primary human 293 cell transmission assays. Cell-free supernatants from primary cocultures were used to infect secondary 293 cultures. M/P, BM cells from mice receiving porcine BM cells alone; $\mathrm{M} / \mathrm{P} / \mathrm{H}, \mathrm{BM}$ cells from mice receiving porcine $\mathrm{BM}$ cells and human thymus/liver; $\mathrm{M} / \mathrm{H}, \mathrm{BM}$ cells from mice receiving human thymus/liver alone; NT, not tested. The results of two independent experiments were identical. 


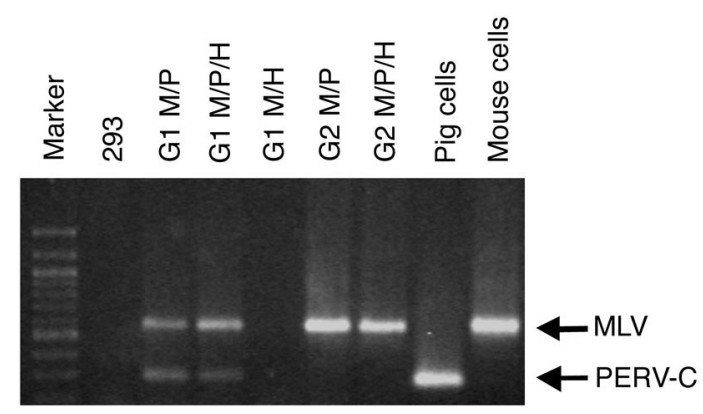

Figure 2

Human 293 cells become transiently positive for PERV-C, and productively infected with MLV, following cocultivation with chimeric bone marrow samples that contain murine cells. Human 293 cells were directly cocultured with chimeric bone marrow containing mouse + pig $(\mathrm{M} / \mathrm{P})$, mouse + pig + human $(\mathrm{M} / \mathrm{P} / \mathrm{H})$, or mouse + human $(\mathrm{M} / \mathrm{H})$ cells. To determine the replication competence of the viruses in this primary culture (G1), a cell-free supernatant preparation was used to further challenge secondary uninfected 293 cells (G2). Cells were tested by PCR for the presence of MLV and PERV-C sequences.

transcripts from the MLV-infected pig cells into human cells. We found that the recovery of MLV-X in the human 293 cells was dependent on the presence of porcine cells in the culture, indicating that the porcine cells contribute in a manner that enhances the transmission of MLV-X. It will prove valuable to determine the mechanism(s) underlying this dependence; for example, studies are needed to investigate whether cell-cell or viral interactions are responsible for the enhanced MLV-X transmission.

To develop a robust murine model for PERV infection in light of these data, it will be necessary to identify lines of mice that do not produce replication-competent MLV and that are also permissive for one or more of the human-tropic subgroups of PERV. While pseudotyping appears to be a significant issue for the interpretation of infectivity data resulting from transplant procedures involving pig cells, it is likely to be less of a complication for cell-free virus infectivity studies. Solely based on the expression of functional receptors in cell lines, a number of animal species might be considered suitable candidates for in vivo studies of PERV (26). Thus far, despite stringent attempts to infect immunosuppressed animals from several species with PERV, infection has not been achieved, suggesting that post-receptor blocks may affect PERV replication $(12,16,33)$. However, because the expression of PERV-A receptors on murine cells renders them fully susceptible to PERV replication (32), it should be possible to develop PERV transmission models via the prudent selection of mouse lines and the production of transgenic mice expressing PERV receptors.

In summary, we have shown that porcine xenografts that lack human-tropic PERV retain a nontransmitting phenotype toward human cells, despite intimate contact over extended periods in an immunosuppressed xenogeneic environment. The absence of direct human cell infection provides encouragement with respect to the potential safety of using pigs that do not produce humantropic PERV as source animals for transplantation to humans.

\section{Methods}

Animal tissues and transplants. Transgenic mice on a NOD/LtSz-SCID/SCID background (NOD/SCID-Tg) that produce porcine IL-3, GM-CSF, and stem cell factor, were generated by backcrossing the transgenic founders (on a mixed NIH Swiss $\times$ FVB background) to NOD/LtSz-SCID/SCID mice (The Jackson Laboratory) for 8-10 generations, as previously described (34). We used inbred Massachusetts General Hospital miniature swine (35) as porcine tissue donors and prepared porcine PBMCs and PAECs from adult swine as described previously $(27,36)$. Human fetal thymus and liver tissues (17- to 20-week-old fetuses) were obtained from Advanced Bioscience Resource Inc.

NOD/SCID-Tg mice were conditioned with 3-Gy whole-body irradiation, followed by intravenous injection of $1 \times 10^{8}$ porcine $\mathrm{BM}$ cells on the same day. Human fetal thymus/liver fragments $\left(\sim 1 \mathrm{~mm}^{3}\right)$ were implanted under the recipient kidney capsule 3 days after whole-body irradiation, as described elsewhere (24). Protocols involving human tissues and animals were approved by the Institutional Review Boards of the Massachusetts General Hospital for Human Studies and for Research Animal Care.

Cell staining and flow cytometry. We determined the level of porcine and human chimerism by flow cytometry using anti-pig pan tissue $\mathrm{mAb} 1030 \mathrm{H}$ 1-19 (Research Diagnostics Inc.), anti-HLA class I antibody (w6/32, Leinco), anti-human CD45 antibody (BD Biosciences - Pharmingen), anti-mouse CD45 antibody (BD Biosciences - Pharmingen), and appropriate isotype control mAbs (24). Analysis was performed on a FACSCalibur (BD). To sort human cells, we stained recipient BM cells with FITC-conjugated antibod-

\section{Table 4}

Amino acid alignment of the amino terminus of the MLV, derived from NOD/SCID mice, which infects 293 cells

$\begin{array}{ll}\text { NOD/SCID } & \text { YCGKWGCETTGQAYWKPSSSWDLISLKRGNTPKDQ------GPCYDSS- } \\ \text { Xenotropic } & \text { YCGKWGCETTGQAYWKPSSSWDLISLKRGNTPKDQ-----GPCYDSS- } \\ \text { Amphotropic } & \text { YCGKWGCETTGQAYWKPTSSWDLISLKRGNTPWDTGCSKVACGPCYDLSK } \\ \text { Ecotropic } & \text { YCASWGCETTGRVYWKPSSSWDYITVDNNLTSNQA----------- } \\ \text { NOD/SCID } & \text { VSSGVQGATPGGRCNPLVLEFTDAGKKAS-WDAPKVWGLRLYRSTGADPV } \\ \text { Xenotropic } & \text { VSSGVQGATPGGRCNPLVLEFTDAGKKAS-WDAPKVWGLRLYRSTGADPV } \\ \text { Amphotropic } & \text { VSNSFQGATRGGRCNPLVLEFTDAGKKAN-WDGPKSWGLRLYR-TGTDPI } \\ \text { Ecotropic } & \text { V-QVCKDNK---WCNPLAIRFTNAGKQVTSWTTGHYWGLRLYV-SGQDPG } \\ \text { NOD/SCID } & \text { TRFSLTRQVLNVGPRVPIGPNPVITEQLPPSQPVQIMLP-RPP------H } \\ \text { Xenotropic } & \text { TRFSLTRQVLNVGPRVPIGPNPVITEQLPPSQPVQIMLP-RPP-----H } \\ \text { Amphotropic } & \text { TMFSLTRQVLNVGPRVIGPNPVLPDQRLPSSPIEIVPAPQPPSPLNTSY } \\ \text { Ecotropic } & \text { LTFGIRLSYQNLGPRIPIGPNPVLADQLSFPLPNPLPKPAKSP------ } \\ \text { NOD/SCID } & \text { PPPSGAASMVPGAPPPSQQP--GTGDRLLNLVKGAYQALNLTSPDRTQEC } \\ \text { Xenotropic } & \text { PPPSGAASMVPGAPPPSQQP--GTGDRLLNLVKGAYQALNLTSPDRTQEC } \\ \text { Amphotropic } & \text { PPSTTSTPSTSPTSPSVPQPPPGTGDRLLALVKGAYQALNLTNPDKTQEC } \\ \text { Ecotropic } & \text { PASSSTPTLISPSPTPTQPPPAGTGDRLLNLVQGAYQALNLTNPDKTQEC } \\ \text { NOD/SCID } & \text { WLCL } \\ \text { Xenotropic } & \text { WLCL } \\ \text { Amphotropic } & \text { WLCL } \\ \text { Ecotropic } & \text { WLCL }\end{array}$

The MLV isolate that grew in 293 cells possesses high sequence similarity to xenotropic MLV (CWM; M59793), and less to amphotropic (AAA46515) or ecotropic MLV (Z11128). At the nucleotide level, we detected a single conservative base change between the NOD/SCID-derived MLV sequence (GenBank accession number GI 332080) and the MLV-X sequence. 
Table 5

In vitro transmission analyses of chimeric bone marrow cultures

\begin{tabular}{lccccc} 
& \multicolumn{5}{c}{ RT activity } \\
Sample & $(\mu \mathrm{U} / \mathrm{ml})$ & PERV-A & PERV-B & PERV-C & MLV \\
$293 \mathrm{M} / \mathrm{P} / \mathrm{H}$ & 29,000 & - & - & - & + \\
$293 \mathrm{M} / \mathrm{P}$ & 51,000 & - & - & - & + \\
$293 \mathrm{M} / \mathrm{H}$ & $<60$ & - & - & - & - \\
$293 \mathrm{P} / \mathrm{H}$ & $<60$ & - & - & - & - \\
$293 \mathrm{H}$ & $<60$ & - & - & - & - \\
$293 \mathrm{P}$ & $<60$ & - & - & - & - \\
$293 \mathrm{M}$ & $<60$ & - & - & - & - \\
\hline
\end{tabular}

Shown are PCR analysis results of 293 cells following in vitro coculture with cells from the species indicated. The human 293 cell cultures were screened by PCR to confirm that residual pig or murine cells were no longer present in the culture at the time of analysis. $\mathrm{M} / \mathrm{P} / \mathrm{H}$, mouse $\mathrm{BM}$ cells + pig BM cells + human fetal liver cells; M/P, mouse + pig BM cells; $\mathrm{M} / \mathrm{H}$, mouse $\mathrm{BM}$ cells + human fetal liver cells; $\mathrm{M}$, mouse BM cells; $\mathrm{P}$, pig BM cells; $H$, human fetal liver cells.

ies specific to human CD45 or HLA class I, and then sorted them using a HiPerFACS Vantage Cell Sorter (BD).

In vitro coculture of porcine, buman, and mouse hematopoietic cells. Porcine $\mathrm{BM}$ cells, mouse BM cells, and human fetal liver cells were cocultured in MyeloCult H5100 medium (Stem Cell Technologies) supplemented with porcine cytokines IL-3 $(2 \mathrm{ng} / \mathrm{ml})$, porcine GM-CSF $(5 \mathrm{ng} / \mathrm{ml})$, porcine stem cell factor $(25 \mathrm{ng} / \mathrm{ml})$, human IL-3 $(10 \mathrm{ng} / \mathrm{ml})$, human GM-CSF (1,000 U/ $\mathrm{ml})$, mouse IL-3 $(10 \mathrm{ng} / \mathrm{ml})$, and mouse GM-CSF $(1,000 \mathrm{U} / \mathrm{ml})$. Human and mouse cytokines were purchased from R\&D Systems. The cultures were harvested 8 days after initiation and used for retrovirus transmission assays.

Retrovirus transmission assays. For transmission analysis of BM cells, we established BM cell cultures as described above and seeded $1 \times 10^{6}$ human 293 or ST-IOWA cells (American Type Culture Collection). We supplemented the DMEM culture medium with 50\% RPMI 1640 Medium (Invitrogen Corp.) for the first two weeks of coculture to favor survival of the stromal cells. We followed established methods when performing transmission assays using PBMCs (27). Briefly, we stimulated approximately $1 \times 10^{8}$ PBMCs with phytohemagglutinin and cocultured the cells and associated stimulation medium with subconfluent 293 or ST-IOWA cells in a $75-\mathrm{cm}^{2}$ flask. The PBMCs were left in contact with the target cells for 4-5 days, after which time the culture medium and PBMCs were removed. The target cells were maintained by subculturing as necessary. For retrovirus transmission analysis of PAECs, we cocultured approximately $8 \times 10^{5}$ PAECs with $4 \times 10^{5} 293$ or ST-IOWA cells with subculture as necessary. Where appropriate, cell culture supernatants were passed through a $0.45-\mu \mathrm{m}$ filter in order to serve as cell-free virus supernatants. We determined retroviral infection of cells by the presence of RT activity in the culture supernatant using an indirect ELISA (HS-kit $\mathrm{Mn}^{2+} \mathrm{RT}$ kit; Cavidi Tech AB). We maintained the cell cultures for approximately 60 days before deeming them negative for retroviral infection.

$P C R$. We isolated DNA from pellets of approximately $2 \times 10^{5}$ cells using the QIAamp DNA Blood Mini Kit (QIAGEN). For the detection of PERV, we used subgroup-specific PERV-A, -B, -C, and pan-PERV ( $p o l$ ) primers in $50 \mu \mathrm{l}$ HotStarTaq PCR master mix (QIAGEN). Each reaction contained $5 \mathrm{mM}$ of each primer and $100 \mathrm{ng}$ of genomic DNA. Cycling parameters were $94^{\circ} \mathrm{C}$ for 15 minutes, then 35 cycles of the following: $94^{\circ} \mathrm{C}$ for 10 seconds, $60^{\circ} \mathrm{C}$ for 30 seconds, $75^{\circ} \mathrm{C}$ for 30 seconds, and $5^{\circ} \mathrm{C}$ for 5 minutes. We used the same conditions for the detection of MLV using specific env primers with the exception of a $55^{\circ} \mathrm{C}$ annealing temperature. The primer sequences were as follows: PERV-A sense 5'-CCTACCAGTTATAATCAATTTAATTATGGC-3';
PERV-A antisense 5'-AGGTTGTATTGTAATCAGAGGGG-3'; PERV-B sense 5'-TTCTGTAGGAGATGGAGCTGC-3'; PERV-B antisense 5'-TGGTAGGAATCAATCCAGTGG-3'; PERV-C sense 5'-CTGACCTGGATTAGAACTGGAAG-3'; PERV-C antisense 5'-TATGTTAGAGGATGGTCCTGGTC-3'; pan-PERV sense 5'-TGCAGGAAACCTCGAGACTC-3'; pan-PERV antisense 5'-TAACGTGGGATGCATGGATC-3'; pan-MLV sense 5'-KCTACTGTGSCWMWTGGGGMTG-3'; pan-MLV antisense 5'-TAACGTGGGATGCATGGATC-3'; swine leukocyte antigen (SLA) sense 5'-GCCCTGGGCTTCTACCCTAA-3'; SLA antisense 5'-TCTCAGGGTGAGTGGCTCCT-3'; CC chemokine receptor 5 (CCR5) sense 5'-TACCTGCTCAACCTGGCCAT-3'; CCR5 antisense 5'-TTCCAAAGTCCCACTGGGC-3'.

We performed quantitative PCR for PERV pol using an ABI 7700 (Applied Biosystems) with $400 \mathrm{nM}$ each of the sense (5'-AGCTCCGGGAGGCCTACTC-3') and anti-sense ( $5^{\prime}$-ACAGCCGTTGGTGTGGTCA-3') primers, as well as $100 \mathrm{nM}$ of the fluorogenic TaqMan probe (5' FAMCCACCGTGCAGGAAACCTCGAGACT-TAMRA 3'). Each sample was assayed in triplicate. Quantification standards, consisting of serially diluted PERV pol DNA amplicons, were run simultaneously. The cycling conditions were as follows: 1 cycle at $50^{\circ} \mathrm{C}$ for 2 minutes; 1 cycle at $95^{\circ} \mathrm{C}$ for 10 minutes; 50 cycles at $94^{\circ} \mathrm{C}$ for 20 seconds, and a hold at $60^{\circ} \mathrm{C}$ for $1 \mathrm{~min}$. The dynamic range of the assay is quantitative between 6.6 million and 66 copies per sample. Pig MHC class I gene primers and probe were developed as internal controls for porcine cellular DNA $(37,38)$. Primers and probe were derived from the pig MHC gene and are as follows: MHC sense, 5'-GCCCTGGGCTTCTACCCTAA-3'; MHC antisense, 5'-TCTCAGGGTGAGTGGCTCCT-3'; probe, 5'-6FAM-CCAGGACCAGAGCCAGGACATGGAGCTCGT-TAMRA-3'. Quantitative sensitivity was 3 copies per reaction. Quantification of pig MHC served as a control for the nucleic acid input amount and for nonspecific inhibition. A more sensitive qualitative PCR control for pig centromeric DNA (present at 1,000-2,000 copies per cell) was also used to detect both the presence of pig nucleic acids in human or murine samples and/or the presence of inhibition of the PCR reaction by the sample tested (sense, 5'-TAGCCATGCTGCATGTAATGC-3'; antisense, 5'-GGAGCGTGGCCCAAT-3'). Each assay included an internal amplimer control fragment to detect inhibition of the PCR assay, which could be misinterpreted as a negative result in the absence of such internal controls.

GenBank accession number. The nucleotide and amino acid sequence of the MLV isolated from NOD/SCID-Tg mice has been deposited at GenBank (accession number AY366074).

\section{Acknowledgments}

We thank F. Preffer and D. Dombkowski for flow cytometry analysis; H.-J. Schuurman and J. Greenstein for critical review of this manuscript; and L. Wang and K. Suling for excellent technical assistance. This study was supported by Immerge BioTherapeutics Inc. (to C. Patience and J.C. Wood), by the Public Health Services grant NIH-NIAID PO1-AI45897 (to J.A. Fishman), and by the Juvenile Diabetes Foundation International grants JDRF1-2001-770 and JDRF1-999-573 (to Y.-G. Yang).

Received for publication April 22, 2004, and accepted in revised form June 29, 2004.

Address correspondence to: Yong-Guang Yang, Transplantation Biology Research Center, Massachusetts General Hospital/ Harvard Medical School, MGH-East, Building 149, 13th Street, Boston, Massachusetts 02129, USA. Phone: (617) 726-6959; Fax: (617) 724-9892; E-mail: yongguang.yang@tbrc.mgh.harvard.edu.

J.A. Fishman and C. Patience contributed equally to this work. 
1. Sachs, D.H., Sykes, M., Robson, S.C., and Cooper, D.K. 2001. Xenotransplantation. Adv. Immunol. 79:129-223.

2. Bach, F.H., et al. 1998. Uncertainty in xenotransplantation: individual benefit versus collective risk Nat. Med. 4:141-144.

3. Fishman, J.A. 1998. Infection and xenotransplantation. Developing strategies to minimize risk. Ann. N. Y. Acad. Sci. 862:52-66.

4. Le Tissier, P., Stoye, J.P., Takeuchi, Y., Patience, C., and Weiss, R.A. 1997. Two sets of human-tropic pig retrovirus. Nature. 389:681-682.

5. Akiyoshi, D.E., et al. 1998. Identification of a fulllength cDNA for an endogenous retrovirus of miniature swine. J. Virol. 72:4503-4507.

6. Patience, C., Takeuchi, Y., and Weiss, R.A. 1997. Infection of human cells by an endogenous retrovirus of pigs. Nat. Med. 3:282-286.

7. Wilson, C.A., et al. 1998. Type C retrovirus released from porcine primary peripheral blood mononuclear cells infects human cells. J. Virol. 72:3082-3087.

8. Wood, J.C., et al. 2004. Identification of exogenous forms of human-tropic porcine endogenous retrovirus in miniature swine. J. Virol. 78:2494-2501.

9. Clemenceau, B., Jegou, D., Martignat, L., and Sai, P. 2002. Microchimerism and transmission of porcine endogenous retrovirus from a pig cell line or specific pathogen-free pig islets to mouse tissues and human cells during xenografts in nude mice. Diabetologia. 45:914-923.

10. Deng, Y.M., Tuch, B.E., and Rawlinson, W.D. 2000. Transmission of porcine endogenous retroviruses in severe combined immunodeficient mice xenotransplanted with fetal porcine pancreatic cells. Transplantation. 70:1010-1016.

11. van der Laan, L.J., et al. 2000. Infection by porcine endogenous retrovirus after islet xenotransplantation in SCID mice. Nature. 407:90-94.

12. Specke, V., et al. 2002. Virus safety in xenotransplantation: first exploratory in vivo studies in small laboratory animals and non-human primates. Transpl. Immunol. 9:281-288.

13. Switzer, W.M., et al. 2001. Lack of cross-species transmission of porcine endogenous retrovirus infection to nonhuman primate recipients of porcine cells, tissues, or organs. Transplantation. 71:959-965.

14. Winkler, M.E., et al. 2000. Porcine endogenous retrovirus is not transmitted in a discordant por- cine-to-cynomolgus xenokidney transplantation model with long-term survival of organ recipients. Transplant. Proc. 32:1162.

15. Loss, M., et al. 2001. Analysis of potential porcine endogenous retrovirus (PERV) transmission in a whole-organ xenotransplantation model without interfering microchimerism. Transpl. Int. 14:31-37.

16. Specke, V., Plesker, R., Coulibaly, C., Boller, K., and Denner, J. 2002. Productive infection of a mink cell line with porcine endogenous retroviruses (PERVs) but lack of transmission to minks in vivo. Arch. Virol. 147:305-319.

17. Elliott, R.B., et al. 2000. No evidence of infection with porcine endogenous retrovirus in recipients of encapsulated porcine islet xenografts. Cell Transplant. 9:895-901.

18. Heneine, W., et al. 2001. Evidence of porcine endogenous retroviruses in porcine factor VIII and evaluation of transmission to recipients with hemophilia. J. Infect. Dis. 183:648-652.

19. Heneine, W., et al. 1998. No evidence of infection with porcine endogenous retrovirus in recipients of porcine islet-cell xenografts. Lancet. 352:695-699.

20. Dinsmore, J.H., Manhart, C., Raineri, R., Jacoby, D.B., and Moore, A. 2000. No evidence for infection of human cells with porcine endogenous retrovirus (PERV) after exposure to porcine fetal neuronal cells. Transplantation. 70:1382-1389.

21. Paradis, K., et al. 1999. Search for cross-species transmission of porcine endogenous retrovirus in patients treated with living pig tissue. Science. 285:1236-1241.

22. Abe, M., Qi, J., Sykes, M., and Yang, Y.G. 2002. Mixed chimerism induces donor-specific $\mathrm{T}$ cell tolerance across a highly disparate xenogeneic barrier. Blood. 99:3823-3829.

23. Pitkin, Z., and Mullon, C. 1999. Evidence of absence of porcine endogenous retrovirus (PERV) infection in patients treated with a bioartificial liver support system. Artif. Organs. 23:829-833.

24. Lan, P., et al. 2004. Induction of human T cell tolerance to porcine xenoantigens through mixed hematopoietic chimerism. Blood. 103:3964-3969.

25. McIntyre, M.C., Kannan, B., Solano-Aguilar, G.I., Wilson, C.A., and Bloom, E.T. 2003. Detection of porcine endogenous retrovirus in cultures of freshly isolated porcine bone marrow cells. Xenotransplantation. 10:337-342.

26. Takeuchi, Y., et al. 1998. Host range and interference studies of three classes of pig endogenous retrovirus. J. Virol. 72:9986-9991.

27. Oldmixon, B.A., et al. 2002. Porcine endogenous retrovirus transmission characteristics of an inbred herd of miniature swine. J. Virol. 76:3045-3048.

28. Suzuki, T., Yanagihara, K., Yoshida, K., Seido, T., and Kuga, N. 1977. Infectious murine type-C viruses released from human cancer cells transplanted into nude mice. Gann. 68:99-106.

29. Todaro, G.J., Arnstein, P., Parks, W.P., Lennette, E.H., and Huebner, R.J. 1973. A type-C virus in human rhabdomyosarcoma cells after inoculation into NIH Swiss mice treated with antithymocyte serum. Proc. Natl. Acad. Sci. U. S. A. 70:859-862.

30. Weiss, R.A. 1984. Experimental biology and assay of RNA tumor viruses. In RNA Tumor Viruses. R.A. Weiss, N. Teich, H.E. Varmus, and J.M. Coffin, editors. Cold Spring Harbor Laboratory. Cold Spring Harbor, New York, USA. 209-260.

31. Ritzhaupt, A., van der Laan, L.J., Salomon, D.R., and Wilson, C.A. 2002. Porcine endogenous retrovirus infects but does not replicate in nonhuman primate primary cells and cell lines. J. Virol. 76:11312-11320.

32. Ericsson, T.A., et al. 2003. Identification of receptors for pig endogenous retrovirus. Proc. Natl. Acad. Sci. U. S. A. 100:6759-6764.

33. Specke, V., Tacke, S.J., Boller, K., Schwendemann, J., and Denner, J. 2001. Porcine endogenous retroviruses: in vitro host range and attempts to establish small animal models. J. Gen. Virol. 82:837-844.

34. Chen, A.M., et al. 2000. Porcine stem cell engraftment and seeding of murine thymus with class $\mathrm{II}^{+}$cells in mice expressing porcine cytokines: Toward tolerance induction across discordant xenogeneic barriers. Transplantation. 69:2484-2490.

35. Sachs, D.H., et al. 1976. Transplantation in miniature swine. I. Fixation of the major histocompatibility complex. Transplantation. 22:559-567.

36. Martin, U., et al. 1998. Expression of pig endogenous retrovirus by primary porcine endothelial cells and infection of human cells. Lancet. 352:692-694.

37. Sullivan, J.A., Oettinger, H.F., Sachs, D.H., and Edge, A.S. 1997. Analysis of polymorphism in porcine MHC class I genes: alterations in signals recognized by human cytotoxic lymphocytes. J. Immunol. 159:2318-2326.

38. Mueller, N.J., et al. 2002. Activation of cytomegalovirus in pig-to-primate organ xenotransplantation. J. Virol. 76:4734-4740. 